\title{
Analysis of the convective drying of residual sludge: from the experiment to the simulation
}

\author{
H. Amadou ${ }^{1}$, C. Beck ${ }^{1}$, R. Mose ${ }^{1}$, C. Vasile $^{2}$, A.-G. Sadowski ${ }^{1}$ \\ \& J.-B. Poulet ${ }^{2}$ \\ ${ }^{1}$ Laboratoire de Systèmes Hydrauliques Urbains, Strasbourg, France \\ ${ }^{2}$ Laboratoire de Génie de conception, Strasbourg, France
}

\begin{abstract}
The drying of residual sludge is a current environmental problem not sufficiently described in the literature, hence research investigations on this drying process are required. Sun drying sludge whilst covered is becoming increasingly attractive for small and medium sized wastewater treatment plants. The control of the quality of the dry product is becoming more and more necessary in order to ensure effectivity. Then new mathematical models should integer these requirements and consider the phenomena of shrinkage. This work gives a mathematical formulation of the different transfer phenomena (heat, mass), which describe the process. The model tries to be relatively simple but sufficiently complete in order to predict and analyze the distribution of temperature, and the moisture during the process. The developed nonlinear differential equations were solved by the classical fourth-order Runge-Kutta method. A validation of these results is achieved by the comparison of the numerical and experimental data.

Keywords: residual urban sludge, drying kinetics, forced convection, numerical simulation, mass and heat transfer.
\end{abstract}

\section{Introduction}

The treatment of effluent from industrial and domestic activities generates large amounts of activated sludge. Due to environmental and economic considerations, the reduction and reuse of this waste are nowadays needed. Many types of processing equipment (filters, centrifuges, dryers, incinerators, etc.) [1] are used. Mechanical solid - liquid separation devices such as filters or centrifuges are not 
always sufficient to ensure high dehydration [1]. To comply with these new requirements for the sludge treatment, usage and disposal, a low moisture content within the material is usually required. Therefore a convective drying step is often necessary.

The convective drying of sludge is considered in this paper. A model based on experimental laboratory data is proposed to simulate the transfer phenomena during the drying of sludge.

From several experiments, the drying characteristic curve was deduced, which allowed the main behaviour of sludge for non tested aerothermic conditions to be extrapolated. The numerical model was then validated by comparing the results with those found experimentally.

\section{Material and methods}

\subsection{Experimental equipment}

The drying experiments were carried out in a climatic chamber. This experimental device makes it possible to have a controlled aerothermic condition that can be varied during experiments.

The air-flow conditions (temperature, relative humidity and velocity) were kept constant for each experiment. The weight and temperature of the sample were recorded on a computer.

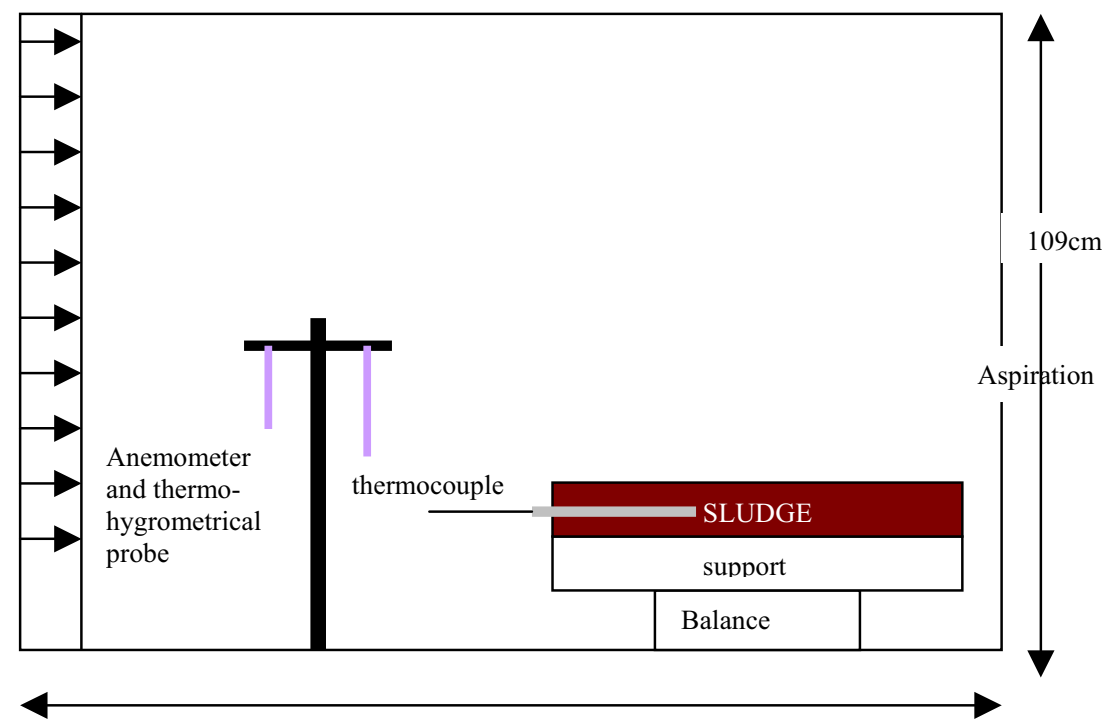

$180 \mathrm{~cm}$

Figure 1: Climatic box. 
The whole device comprises:

- The climatic box with a sectional area of $180 \mathrm{~cm} \times 100 \mathrm{~cm}$ and a height of $109 \mathrm{~cm}$

- A tray with a surface area of $47 \mathrm{~cm} \mathrm{x} 40 \mathrm{~cm}$, inserted into the climatic box and placed on an electronic balance with an accuracy of $0.01 \mathrm{~g}$, provided with an analogical output

- An adjustable flow ventilator via a variable generator. The air velocity was measured by two FVA645TH2/TH3 thermal anemometers with an accuracy of $0.01 \mathrm{~m} / \mathrm{s}$. One of them was placed upstream of the tray and the other one was placed downstream.

- An MT8636HR thermohygrometric sensor with an accuracy of $2 \%$, measuring the temperature and the moisture of the air circulating in the climatic box, in order to monitor the temperature and humidity set points in the climatic chamber.

- A K-type thermocouple with a large standard T 150 handle, placed at a given depth of sludge. This thermocouple was used for tracking temperature changes in the sludge during the test.

- A data-acquisition unit connected to a microcomputer, running the AmrCONTROL software application, stores and processes the data.

\subsection{Experimental protocol}

The principle of the tests is simple. The airflow conditions (temperature, relative humidity and velocity) are set, then, once the system has stabilized, the sludge is spread in a thin layer over the tray in the climatic box. The weight and temperature of the sample are recorded by a computer.

At the end of the experiment, the average moisture content of the sludge was determined by drying at $105^{\circ} \mathrm{C}$ for $24 \mathrm{~h}$.

\section{Mathematical formulation of the problem}

\subsection{Modelling of the drying unit}

The aim was to study a mathematical model of the drying of a fine layer of sludge, with the operating of two transfer modes, namely heat and mass. The study called for knowledge of the exchange surface and transfer coefficients. The system model was reduced to a one-dimensional study along the direction of the air flowing through the sludge.

\subsection{Simplifying hypotheses}

To simplify the study of the heat and mass transfers that had been coupled in the drying system, the following hypotheses $[2,3]$ were assumed valid:

- radiation exchange inside the enclosure could be ignored

- convective exchange between the air and the walls of the climatic enclosure could be ignored 
- the temperature and water content of the product were assumed to be uniform

- the temperature, humidity and speed of the air in contact with the sludge layer were assumed to be constant

\subsection{Model equations}

The model draws on the methods of the mechanics of continuous media applied to hygroscopic porous media, which consist in locally expressing the laws of the conservation of mass and energy and averaging them in a reference volume $[2,3]$.

The equations that govern the exchange of heat and mass in the system are discussed in the following sections.

\subsubsection{Conservation of energy as regards the sludge}

The variation of the enthalpy of the sludge is equal to the sum of the powers exchanged by convection with the air and the energy used to vaporise the water in the sludge:

$$
m_{b} C p{ }_{b} \frac{d T_{b}}{d t}=h S\left(T_{a i}-T_{b}\right)-L_{v} \dot{m}
$$

where:

$$
\begin{gathered}
C_{p b}=\frac{C_{\text {panhydre }}+X C_{p e}}{1+X} \text { is the specific heat of the sludge } \\
C_{\text {panhydre }}=1350 \mathrm{~J} / \mathrm{Kg} \cdot \mathrm{K} \text { is the specific heat of the anhydrous sludge }
\end{gathered}
$$

$h=\frac{N u \lambda}{l}$ is the coefficient of convection between the sludge and the air

$$
N u=2,161 \operatorname{Re}^{0.5} \operatorname{Pr}^{1 / 3} \text { is the Nusselt number [4] }
$$

The specific heat of the anhydrous sludge was determined with a differential calorimeter depending on the temperature. The influence of the temperature on the specific heat of the anhydrous sludge was negligible [5].

\subsubsection{Conservation of the mass}

The drying kinetics equation represents the weight assessment of the sludge:

$$
\dot{m}=m s\left(-\frac{d X}{d t}\right)
$$

where: $m s$ is the dry matter in the sludge

$$
\left(-\frac{d X}{d t}\right) \text { is the drying speed determined experimentally for the sludge. }
$$


The drying kinetics were determined in different operating conditions and then standardised with the help of the Van Meel transformation [6] given below:

$$
\left(-\frac{d X}{d t}\right)=\left(-\frac{d X}{d t}\right)_{1} f\left(X_{r}\right)
$$

where: $f\left(X_{r}\right)=A_{1} X_{r}+A_{2} X_{r}^{2}+A_{3} X_{r}^{3}$ is the reduced drying speed

$$
\begin{aligned}
& X_{r}=\frac{X-X_{e q}}{X_{c r}-X_{e q}} \text { is the reduced water content } \\
& \left(-\frac{d X}{d t}\right)_{1} \text { is the constant phase speed }
\end{aligned}
$$

Constants, $A_{1}, A_{2}, A_{3}$ were determined experimentally for fixed air characteristics (figure 2 and table 1 ).

To solve the equations of this model (mass and heat assessment), the classical fourth-order Runge-Kutta method was used.

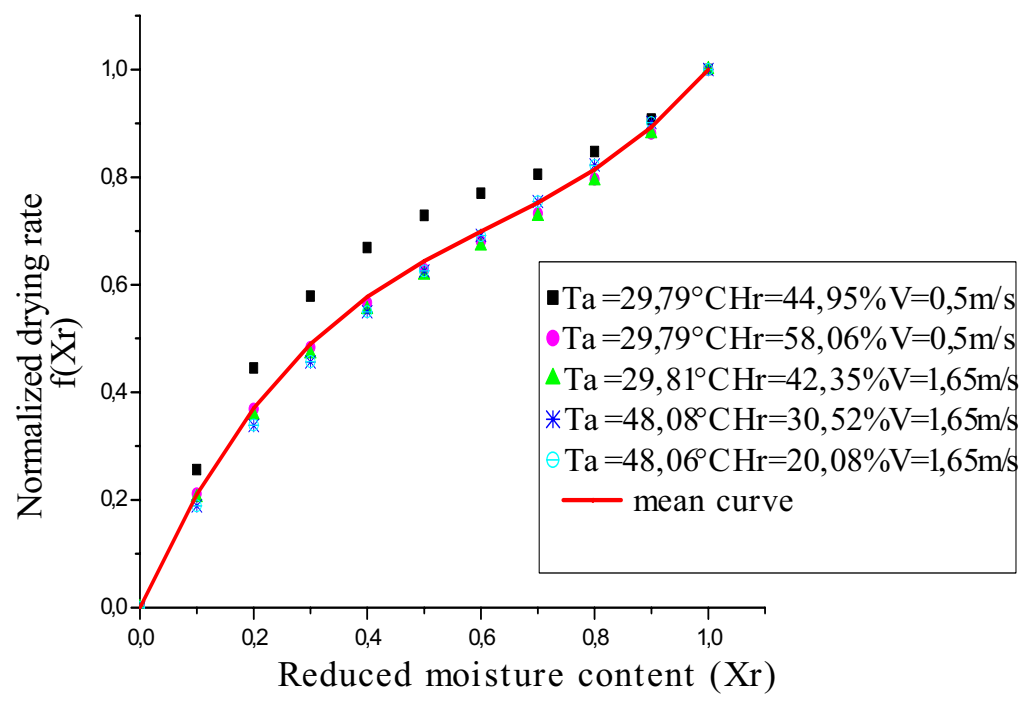

Figure 2: $\quad$ Characteristic drying curve.

\section{Results}

\subsection{Model parameters: identification of the curve characteristic of drying}

The drying kinetic is the main required datum of the model. It must be proposed as a mathematical function of evaporation mass flux density versus the sludge moisture content including the effect of air properties. It is usually derived from experimental investigations. The air properties were introduced into the 
mathematical function in term of a constant rate period (usually isenthalpic) corresponding to the evaporation of free water at the surface of the sludge.

$$
\left(\frac{d X}{d t}\right)_{1}=\frac{h S}{m_{s} L_{v}}\left(T_{a}-T_{h b}\right)
$$

The curve obtained experimentally was $X=f(t)$; then $(-d X / d t)=f(t)$ could be obtained by calculating this derivative directly from the experimental points or after smoothing curve $X=f(t)$.

In order to describe the drying kinetics in any and all air conditions, the principle of the characteristic drying curve [8] was used.

The reduced drying speed (characteristic drying curve) (figure 2) was determined from the experiments in that form $[9,10]$ :

$$
f\left(X_{r}\right)=A_{1} X_{r}+A_{2} X_{r}^{2}+A_{3} X_{r}^{3}
$$

Table 1 contains values, $A_{1}, A_{2}, A_{3}$ determined experimentally.

Table 1: $\quad$ Parameters of the reduced drying speed with their confidence limit (CL).

\begin{tabular}{ccc}
\hline \multicolumn{2}{c}{ Value of parameters } & \multicolumn{2}{c}{ CL at $95 \%$} \\
\hline$A_{1}$ & 2.394 & 0.670 \\
$A_{2}$ & -3.029 & 1.30 \\
$A_{3}$ & 1.635 & 0.660 \\
\hline
\end{tabular}

The actual experimental conditions were injected in the numerical model and the variations of the water content and the surface temperature of the sludge were represented (figure 3).

\subsection{Model validation}

The model validation was carried out through a comparison between predicted variable values and those obtained experimentally (figure). The comparison was made in respect of the changes in the water content and the temperature at the surface of the product.

The slight misfit observed can be attributed to the sum of errors inherent to the experiment investigations and to the simplifying hypothesis and parameters estimation. Nevertheless, one can consider that the mathematical model gives acceptable results.

As regards the changes in the water content of the sludge, the simulation showed a good match with the experimental results.

However, a difference was sometimes found between the theoretical and experimental results in respect of the temperature at the surface of the sludge. 
To explain that difference, the following remarks must be made:

- not all the coefficients of the convective heat exchanges between the sludge and the air were well known;

- the initial conditions taken into account in the model did not always provide a good approximation with the reality;

- the simplifying hypotheses used also help explain the difference seen between the temperature profiles.
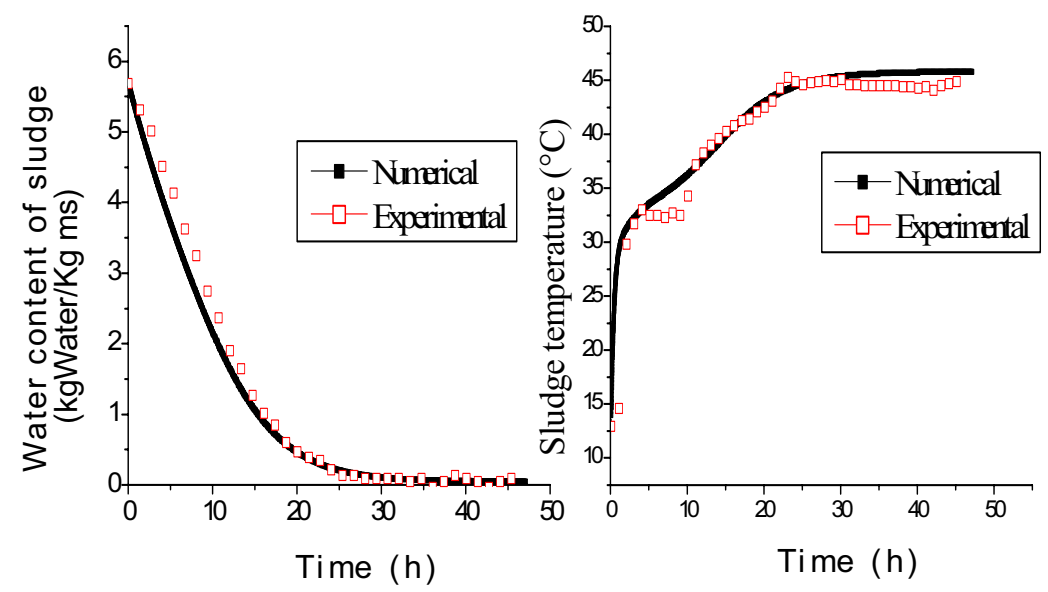

(a)
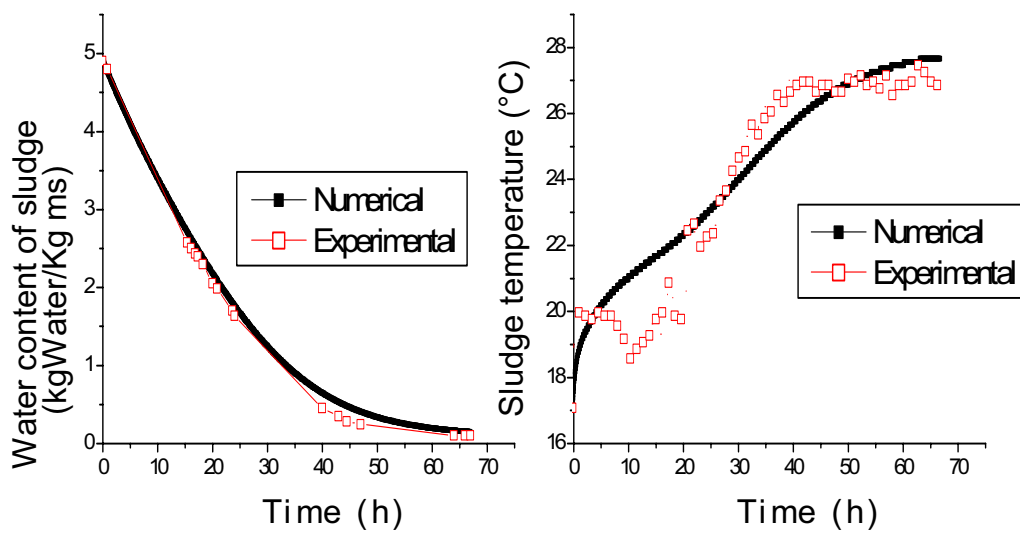

(b)

Figure 3: (a) Comparison between the numerical and experimental results at $\mathrm{Ta}=48.04^{\circ} \mathrm{C} \mathrm{Hr}=30.52 \% \mathrm{~V}=1.65 \mathrm{~m} / \mathrm{s}$. (b) Comparison between the numerical and experimental results at $\mathrm{Ta}=29.7^{\circ} \mathrm{C} \mathrm{Hr}=44.9 \%$ $\mathrm{V}=0.5 \mathrm{~m} / \mathrm{s}$. 


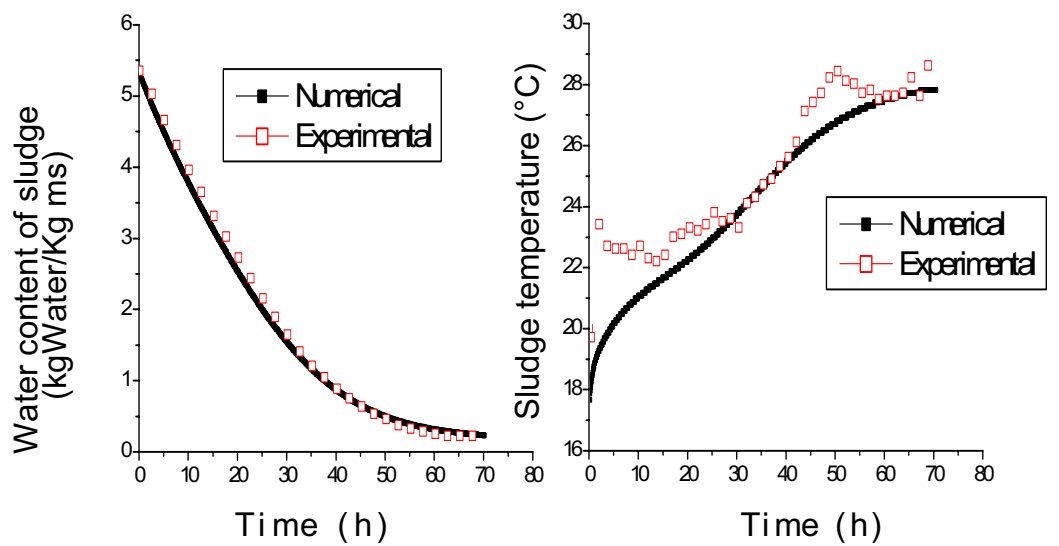

(a)
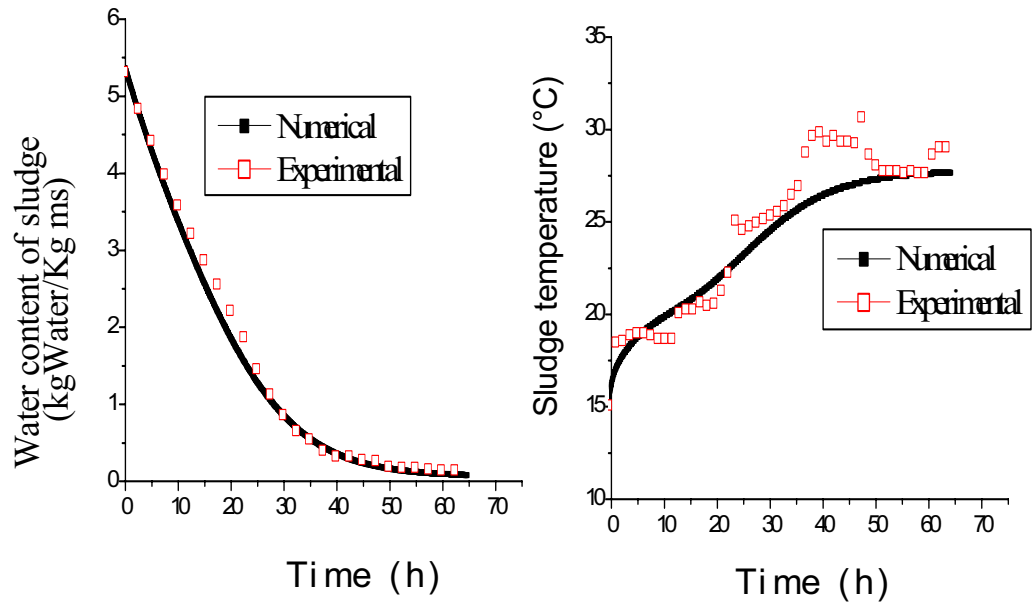

(b)

Figure 4: (a) Comparison between the numerical and experimental results at $\mathrm{Ta}=29.55^{\circ} \mathrm{C} \mathrm{Hr}=58.24 \% \mathrm{~V}=0.944 \mathrm{~m} / \mathrm{s}$. (b) Comparison between the numerical and experimental results at $\mathrm{Ta}=29.71^{\circ} \mathrm{C} \mathrm{Hr}=37.06 \%$ $\mathrm{V}=1.06 \mathrm{~m} / \mathrm{s}$.

\section{Conclusion}

A mathematical unidirectional and dynamic model describing the coupled heat and mass transfers has been established. The water migration from the sample core to the product-air surface is characterized by a front that moves through the clay sample as soon as the external surface rapidly reaches the equilibrium. 
The theoretical and experimental results were compared and a satisfactory match was found in respect of the drying curves. Only the sludge temperature profiles were sometimes different, due to the initial conditions imposed on the model.

\section{Notation}

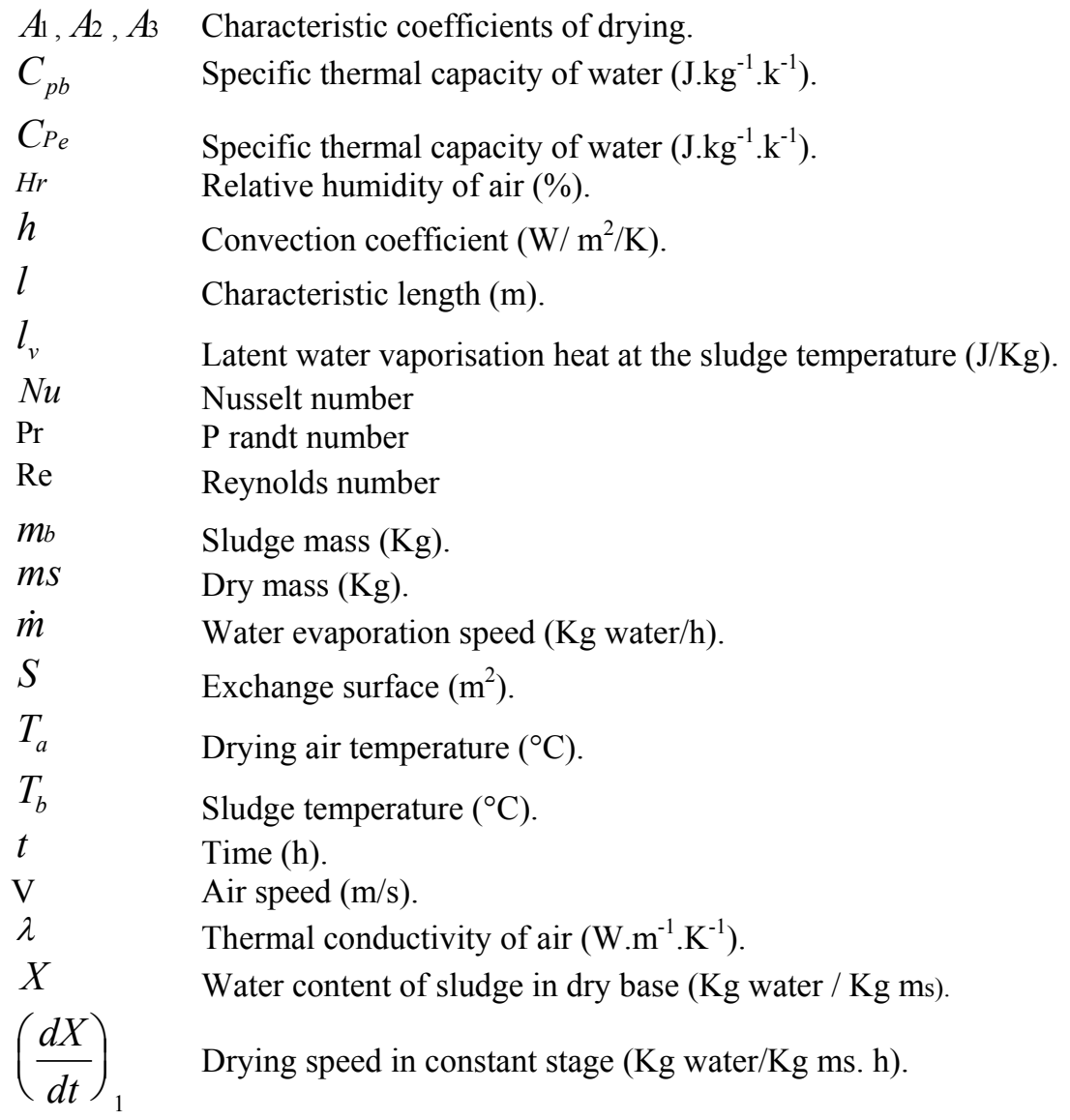

\section{Indices}

$\begin{array}{ll}a & \text { Air } \\ b & \text { Sludge } \\ c r & \text { Critical } \\ e q & \text { Equilibrium (relates to sorption isotherm) } \\ i & \text { Initial }\end{array}$




\section{References}

[1] Vaxelaire J., Cezac P., Moisture distribution in activated sludges: a review Water Research 38 (2004) 2215-2230.

[2] Vaxelaire J., PUIGGALI J.R, Analysis of the drying of residual sludge: From the experiment to the simulation of a belt dryer Drying thechnology, 20(4\&5), 1009-1018 (2002).

[3] Belghit A., Etude numérique d'un séchoir solaire fonctionnant en convection forcée Rev- Gén Therm (1997) 36,837-850 Elsevier.

[4] Sacadura. J.F, Initiation aux transferts thermiques, technique et documentation, paris, 1993.

[5] Vaxelaire J., Bongiovanni J.M and Puiggali J.R., Mechanical dewatering and thermal drying of residual sludge. Environnemental Technology, vol 20 pp 29-36 (1999).

[6] Van meel (D.A.). - Chem. Eng. Sci., 9, p. 36 (1957).

[7] Charreau A, Cavaillé R., Séchage: Théorie et calculs. Techniques de l'ingénieur, traité Génie des procédés, J 2 480-1

[8] Léonard A., Etude du séchage convectif de boues de station d'épuration, suivi de la texture par microtomographie à rayons $\mathrm{X}$, thèses de doctorat, Faculté des sciences appliquées Université de Liège (2003).

[9] Talla A, Jannot Y, Kaspseu C, Nganhou J., Experimental study and modelling of kinetics of drying of tropical fruits. Application to banana and to mango. Wood science, 21 499-518 (2001).

[10] Desomorieux H., Moyne C., Analysis of dryers performance for tropical foodstuffs using the characteristic drying curve concept. In: Drying 92, Elsevier Amsterdam, 834-843 (1992). 